\title{
The Importance of University Students' Perceived Ability to Balance Multiple Roles: A Comparison of Students with and without Disabilities
}

\author{
Maureen J. Reed \\ Ryerson University \\ Deborah J. Kennett \\ Trent University
}

\begin{abstract}
Canadian students have academic and non-academic obligations, and their ability to balance them may impact university experience. Involvement in academic and non-academic activities, and the perception of balancing them was compared between students with and without disabilities. Results revealed that both groups of students participated in employment, social activities, and family obligations. Furthermore, perceived ability to balance academic and non-academic activities was associated with higher academic self-efficacy and resourcefulness in all students. Relative to non-disabled peers, students with disabilities spent fewer hours participating in non-academic activities, had fewer course hours, but studied as many hours. Students with disabilities who had difficulties balancing their multiple roles were less adapted to university. The time to access accommodations for learning may act as a barrier to adaptation. Creating university policies around accommodations for learning would benefit students with disabilities, and the incorporation of resourcefulness and time-management into university curriculum would benefit all students.
\end{abstract}

\section{Résumé}

Les étudiants canadiens ont tous des obligations scolaires et parascolaires, et leur capacité à les équilibrer entre elles peut avoir des répercussions sur leur expérience universitaire. La participation à des activités scolaires 
et parascolaires, et la perception d'arriver à les équilibrer entre elles a été comparée entre étudiants avec handicap et étudiants sans handicap. Les résultats ont démontré que les étudiants avaient tous des obligations professionnelles, sociales et familiales, peu importe s'ils étaient affligés d'un handicap ou non. En outre, la perception de pouvoir équilibrer entre elles les activités scolaires et parascolaires a été associée à une meilleure efficacité scolaire autodidacte et à un meilleur esprit d'initiative chez tous les étudiants. Comparativement à leurs camarades sans handicap, les étudiants avec handicap consacraient moins d'heures à des activités parascolaires, disposaient de moins d'heures de cours, mais étudiaient autant d'heures. Les étudiants avec handicap qui avaient de la difficulté à équilibrer leurs multiples rôles étaient moins adaptés à la vie universitaire. Comme le temps nécessaire pour accéder aux installations d'apprentissage peut constituer une barrière à l'adaptation, l'élaboration de politiques universitaires autour des installations d'apprentissage serait bénéfique pour les étudiants avec handicap. De même, l'intégration del'esprit d'initiative et de la gestion du temps dans le programme d'études universitaires profiterait à tous les étudiants.

\section{Introduction}

Over the last several decades, governments in Canada and other countries have encouraged universities to provide access to higher education to wider segments of the population (Hornsby \& Osman, 2014; Ogilvie \& Eggleton, 2011; Ontario Human Rights Commission, 2005; Prudence \& Li-Tien, 2013; Rossi, 2010). In general, this has meant an increase in the number of students attending university who traditionally did not seek university education. These non-traditional students include, but not exclusively, older students, students whose parents are less educated, students from economically disadvantaged homes, students with family responsibilities, and students with disabilities (Reed, 2016). While there are many benefits to providing higher education to a diverse population, such as employment, innovation, and improved health (Ogilvie \& Eggleton, 2011), studies of non-traditional students' experience reported that they feel unprepared for the rigours of university education (Stebleton \& Soria, 2012), believe they do not fit into the university culture (Collier \& Morgan, 2008), and are a financial burden to their families (Rosado \& David, 2006).

Given increased access to university, the roles of university students have become more complex. Today, almost half of Canadian full-time postsecondary students are employed at least part time, working on average 15.6 hours per week (Marshall, 2010), and the Canadian University Survey Consortium (CUSC) reported that about $16 \%$ work 30 or more hours per week (CUSC, 2011). CUSC (2011) suggested that employment and academic obligations of university students take approximately 41 hours per week. In addition, CUSC reported that $9 \%$ of university students have children, and $53 \%$ volunteer on average four hours per week. These data indicate that university students have multiple roles, and these multiple roles might impact students' ability to perform academically, affect their adaptation to university, and influence their self-efficacy about meeting academic challenges.

One group who shares many traits with other non-traditional student groups, but may have additional academic barriers, are students with disabilities (Reed, Lund-Lucas, \& 
Lewis, 2006). Students with disabilities are a heterogeneous group that includes individuals with physical, sensory, learning, mental health, and chronic illness challenges (Ontario Human Rights Commission, 2008). In Canada, it is estimated that about 22\% of high school students with disabilities attend university, representing approximately 5 to $7 \%$ of the university population (McCloy \& Declou, 2013). Students with disabilities sometimes have low academic self-efficacy (belief in own academic ability; Vogel, Fresko, \& Wertheim, 2007), which may add to their academic stresses. Beyond the multiple roles (academic, social, employment, family) taken on by many university students, those with disabilities often must seek, advocate for, and participate in accommodations for learning (e.g., organizing note takers, accessing audio books, advocating for extensions, learning adaptive technology, etc.), making their adaptation to university more difficult. Researchers have shown that the student obligation to access and advocate for accommodations is commonly a slow, difficult process, and frequently accommodations are inadequate (e.g., poor access to books in electronic format and class notes), complex, and involve long wait times (Eckes \& Ochoa 2005; Reed et al., 2006; Reed \& Curtis 2012). Such obligations increase student stress and workload and likely impact their perception and actual ability to time-manage their multiple roles.

Even for students without disabilities, involvement in multiple roles has been shown to influence students' university experience both positively and negatively (Dunes \& Marx, 2007; Holmes 2008). Positive outcomes include findings showing that participation in extracurricular activities can promote university adaptation and academic satisfaction (Strapp \& Farr, 2010; Webber, Krylow, \& Zhang, 2013) and is associated with higher grades when these activities are co-curricular and emphasize academic skill (Webber et al., 2013). Moreover, part-time employment (less than 15-19 hours/week) does not have a deleterious effect on academic performance relative to those who are not employed (Dunes \& Marx, 2007; King, 1999). Dunes and Marx (2007) found that students who were employed 10 to 19 hours obtained higher grades than those working more or less hours, suggesting that employment forces these students to be organized.

Negative outcomes include students reporting that working while attending university delayed degree completion (Holmes 2008), and those with poor employment-study balance are more prone to burn out (Galbraith \& Merrill, 2015). Yet, Van Rhijn and Lero (2014) found that students believing that they were effective in balancing multiple roles were more likely to report higher academic satisfaction and self-efficacy. Therefore, it may not simply be the number of activities, job hours, and social and family obligations that hinder students' success and well-being. What matters is one's belief in being able to balance multiple roles and having the requisite resourcefulness skill set to do so.

Learned resourcefulness is a set of skills acquired through experience that help regulate internal emotions and responses that can interfere with the execution of a demanding task (e.g., test taking; Akgun \& Ciarrochi, 2003; Goff, 2011; McWhirter, Burrow-Sanchez \& Townsend, 2008). To offset the negative effects of stress in these situations, highly resourceful people use positive self-statements to control emotional and physiological responses, apply a variety of problem-solving methods, and recognize that some solutions may take considerable effort on their part (Rosenbaum, 1980). When resourcefulness is examined specifically within the academic setting, focus is on the students' ability to set academic goals, plan and evaluate alternatives, think positively about academic chal- 
lenges, draw from resources such as the course syllabus, manage course loads effectively, use appropriate study techniques, and apply self-consequences for learning (Kennett \& Keefer, 2006; Kennett \& Reed, 2009). Research confirms that relative to less resourceful students, highly resourceful students better overcome stress to achieve higher grades (Akgun \& Carrochi, 2003), are more adjusted to the academic environment (Kennett \& Keefer, 2006), are less likely to show test anxiety, and less likely to attribute their past academic disappointments to their lack of ability (Kennett, Young, \& Catanzaro, 2009).

As defined above, part of being resourceful is the ability to evaluate options and prioritize. Resourcefulness is probably related to ones' perceived and actual ability to balance their multiple roles. Kennett, Reed, and Stuart (2013) observed that those students who were most able to balance academic and non-academic activities showed higher academic self-efficacy and resourcefulness. Likely the same is true for students with disabilities. Studies showed that alumni with disabilities report that they were best prepared for their later employment by learning how to balance multiple roles at university (Reed et al., 2006), and half to two-thirds of students with learning disabilities have low resourcefulness skills (Reed et al., 2009). However, it is unclear whether students with disabilities and having the same multiple roles as other students plus the additional responsibility of organizing their accommodations to the learning process find it more difficult balancing multiple roles, regardless of their level of resourcefulness.

In summary, this study examined the relative impact of multiple activities on the university experience for students with and without disabilities. These two groups were compared in terms of their involvement in academic and non-academic activities and their perception of their ability able to effectively balance them. We also investigated the moderating role played by this perception on reported grades, academic resourcefulness skills, academic self-efficacy, and university adaptation for students with and without disabilities.

\section{Methods}

\section{Participants}

In total, 147 students with disabilities and 347 students without disabilities participated in this study; however, 2 students with disabilities and 6 students without disabilities were removed because of excessive missing data, leaving a sample size of 486 students. Overall, $28.3 \%$ of those with disabilities and $68.5 \%$ of those without disabilities were in their first year of university study, with the remaining students having completed at least one year of higher education. In both groups, participants were predominantly female (64.8\% with disabilities and $76.2 \%$ without disabilities) and full-time students ( $>83 \%$ ). Mean age for the students with disabilities was 26.0 years $(S D=9.6$; range $=18-65)$ and for students without disabilities 20.7 years $(S D=4.3$; range $=17-54)$.

Based on categorization of disability type used in Canadian Ontario universities and recommended by the Ontario Human Rights Code (Ontario Human Rights Commission, 2008), students with disabilities in this sample reported Learning disability (25.5\%), Attention Deficit Hyperactivity Disorder (16.6\%), multiple disabilities (13.1\%), chronic illness (11.7\%), blindness (3.4\%), mobility issues (3.4\%), psychiatric issues (2.8\%), a disability related to an acquired head injury (2.1\%), or deafness (2.1\%). Twenty-eight individuals did not report their disability type. In this study, students with disabilities were treated as 
a single group and compared to those without disabilities. As noted in the procedure section, all students registered at the centre for students with disabilities were sent a general email asking for participation. Those who wished to participate contacted the researchers. Thus, individuals with particular types of disabilities were not targeted and the number of students within disability categories was too low to make comparisons between types (e.g., blindness versus learning disability). This is acknowledged as a limitation in the discussion. Furthermore, only $\mathbf{1 3 . 1 \%}$ of our sample reported multiple disabilities, yet a large number of Canadians report multiple disabilities (Statistics Canada, 2015). As outlined in the discussion, understanding this group of students would have been advantageous, but our numbers did not allow for disability-type generalizations.

\section{Procedures}

After ethics approval, students with and without disabilities were contacted through the undergraduate psychology research pool and were invited online to participate. This subject pool is a pool of students registered to take Introduction to Psychology and represents students majoring in multiple disciplines and varying in their year of academic study. Other students with disabilities were contacted through the university centre for students with disabilities via email. If they chose to participate, they could do so in person or online. Students opting to participate in person completed the questionnaires electronically, but a researcher was available to assist if needed. A consent form outlining the goals of the investigation was displayed electronically and had to be approved by participants (by button press) before beginning the online questionnaires. Those participating in person were provided with and signed a consent form prior to filling out the electronic questionnaires. After completing the questionnaires, participants were directed electronically to a debriefing page, which contained information about the study and researcher contact information. The debriefing forms and consent forms could be downloaded and printed. The debriefing form and a copy of the consent form was physically provided to all those who participated in person.

\section{Measures}

The background information form. This form collected demographic information, including year of study, current grade point average, full-time or part-time status, disability type, study habits, class attendance, and non-academic activities the student participated in. Students were also asked to rate on a six-point Likert scale how well they believed they balanced their academic activities and non-academic activities: 1 = "not well at all" and 6 = "extremely well." This item has been shown to predict academic resourcefulness for undergraduate students (Kennett et al., 2013).

The Academic Resourcefulness Inventory. This inventory measures academic self-control behaviours (academic coping) and is well established for use in undergraduate populations. It assesses the students' use of positive self-statements to manage academic setbacks ("self-assured when taking an exam/test"), problem solving strategies to cope with academic demands ("good at organizing my time"), and their delay avoidance ("successfully meeting deadlines"). Students rate, on a 7-point Likert scale, their ability or inability to meet academic demands. Scores on this inventory range from 23 to 161, with 
higher scores reflecting greater academic resourcefulness. Scores for postsecondary student populations are normally distributed with a mean score of 108 and a standard deviation of 17 (Kennett 1994; Kennett \& Keefer 2006). Kennett (1994) demonstrated internal reliability, construct and predictive validity, and a 7-month test-retest reliability of 0.75.

The Academic Self-Efficacy Scale. This scale explores student beliefs about their academic abilities and is established for use with undergraduate populations. The nine items of this scale require students to rate themselves on a 6-point Likert scale: 1 = "strongly disagree" to $6=$ "strongly agree" how well each statement describes them (e.g., "I know that I will be able to learn new material"; "I expect to do well”). Scores can range from 9 to 54, with a higher score indicating greater academic self-efficacy (Kennett \&Keefer, 2006). For postsecondary populations a typical mean of about 38 with a standard deviation of 7 is found (Kennett \& Reed, 2009; Kennett \& Keefer, 2006). A 7-month test / test reliability of 0.75 has also been demonstrated (Kennett, 1994).

The University Adaptation Questionnaire. This questionnaire assesses student adjustment to college or university (Crombag 1968) and is a widely-used tool to assess adaptation. The 18-item scale asks students to indicate whether statements are characteristic of their experience at university (e.g., "I feel very much at home here"). Total scores can range from 18 to 108, where higher scores indicate higher adjustment and student samples typically generate a mean score of 71.4 with a standard deviation of 17 (Kennett et al., 2013).

\section{Data Analysis}

Background differences (e.g., differences in number of study hours) and scale responses (e.g., assessment of perceived ability to balance academic and non-academic activities) between students with and without disabilities were analyzed using $t$-tests and chi-square for proportions, where appropriate. To determine whether perceptions of balance had a differential influence on the psychosocial (self-efficacy and academic resourcefulness) and outcome variables (reported grades and university adaptation) for students with and without disabilities, moderating analyses, via hierarchical multiple regression, were conducted. Balance scores were centred to avoid multicollinearity and ranged from -2.66 to 2.33 (see Howell, 2013), with lower balance ideation being below the centred mean of o.

\section{Findings}

\section{Academic Behaviours}

Do students with and without disability show different study habits, school-related behaviours, academic self-efficacy, academic resourcefulness and university adaptation? Table 1 shows comparisons between students with and without disabilities on self-reported class and study behaviours. Although students with disabilities took fewer course hours per week, there was no significant difference in the number of hours they study outside of class relative to students without disabilities, $t(481)=-1.82, p=.07$, Cohen's $d=.18$. Both student groups reported high attendance to classes, though the average attendance for students with disabilities was slightly lower, $t(481)=2.36, p=.02$, Cohen's $d=.23$. 
Table 1. Comparisons between Those with and without Disabilities on Academic Behaviour

\begin{tabular}{lcccc}
\hline Item & $\begin{array}{c}\text { Students without } \\
\text { disability } \\
\text { Mean (SE) }\end{array}$ & $\begin{array}{c}\text { Students with } \\
\text { disability } \\
\text { Mean (SE) }\end{array}$ & Significance $p$ & $\begin{array}{c}\text { Cohen's } \\
\text { effect size }\end{array}$ \\
\hline Number of course hours/week & $14.21(0.29)$ & $11.95(0.56)$ & $<.001$ & 0.37 \\
Number study hours/week & $15.3(0.7)$ & $17.63(1.09)$ & .07 & 0.18 \\
\% Classes Attended & $93.0(0.80)$ & $89.3(1.51)$ & .02 & .23 \\
Self-efficacy & $39.88(0.48)$ & $38.99(0.70)$ & .30 & .10 \\
Resourcefulness & $108.43(1.08)$ & $100.17(1.81)$ & $<.001$ & .40 \\
Adaptation & $73.28(0.84)$ & $79.90(1.43)$ & .14 & .15 \\
Reported GPA & $3.0(0.04)$ & $3.0(.05)$ & .99 & .001 \\
\hline
\end{tabular}

Independent $t$-tests comparing the two student groups on academic self-efficacy, academic resourcefulness (academic coping), university adaptation (university adjustment), and reported grades revealed a significant difference for only the academic resourcefulness variable. Hence, although students with and without disabilities had similar beliefs about their academic capabilities and university adaptation, students with disabilities were significantly less academically resourceful than those without a disability, $t(484)=4.07, p<$ .001 , Cohen's $d=.40$. To determine if the difference in academic resourcefulness was due to particular items on the resourcefulness scale, group differences were examined for the individual items. We found that students with disabilities scored lower on 20 of the 23 items of the Academic Resourcefulness Inventory and significantly so (all comparisons, $p$ $<$.05) on 10 of these items. These significant differences encompassed a breadth of issues: completing exams, meeting deadlines, attending classes and tutorials, study preparation, reviewing notes, being mindful of content, feeling assured in tests, and asking for extensions. Students with disabilities scored less favourably in many of these categories.

\section{Non-Academic Behaviours}

Do students with and without disability show different non-academic related activities? Students were asked to list the types of non-academic activities they participated in and to estimate the number of hours they dedicated to non-academic activities each week. The non-academic activities were categorized into three areas: employment, social activities, and family obligations, as shown in Table 2. Social activities included activities such as sports, clubs, and spending time with friends. However, students were not specifically asked if social activities were on-campus or off-campus activities.

Chi-square analyses revealed no significant differences in the proportion of students with and without disabilities participating in various non-academic activities, $p_{s}>.05$. Students with disabilities, however, dedicated on average fewer hours to these activities than students without disabilities $t(373.46)=2.857, p=.005$; Cohen's $d=.27$. 
Table 2. Comparisons between Those with and without Disabilities on Non-Academic Behaviour

\begin{tabular}{lcccc}
\hline Item & $\begin{array}{c}\text { Students without } \\
\text { disability } \\
\%\end{array}$ & $\begin{array}{c}\text { Students with } \\
\text { disability } \\
\%\end{array}$ & & \\
\hline Employment & 60.5 & 56.2 & & \\
Social activities & 64.3 & 73.7 & & \\
Family obligations & 32.1 & 27.7 & Cohen's effect \\
Item & Students without & Student with dis- & Significance \\
& disability & ability & Size \\
Mean (SE) & Mean (SE) & .27 \\
\hline Hours spent per week & $21.57(1.17)$ & $16.74(1.22)$ & .005 & \\
\hline
\end{tabular}

\section{Balancing Multiple Roles}

How well do students with and without disabilities perceive they balance their academic and non-academic activities? On average, students with disabilities perceived themselves somewhat unable to balance their academic and non-academic activities $(M=3.39, S E=0.11), t(484)=3.08, \mathrm{p}=.002$, Cohen's $d=.31$, while students without disabilities perceived themselves somewhat able to balance these activities $(M=$ 3.78; $S E=.07)$. Where $47.6 \%$ of students with disabilities perceived they could at least somewhat balance academic and non-academic activities $\chi^{2}(1)=6.5, p=.011$, more$60.1 \%$ - of students without disabilities perceived they could do the same.

Bivariate relationships between perceptions of balance with academic self-efficacy, university adaptation, academic resourcefulness, and reported grade for students with and without disabilities. For both groups, significant positive relationships were observed between perceptions of being able to balance multiple roles and academic self-efficacy, university adaptation, and academic resourcefulness, as shown in Table 3. With the exception of the correlation between balance and university adaptation, correlations between the two groups were similar in strength and indicated that students with greater perceptions of their ability to balance multiple roles were more academically efficacious and resourceful. Nevertheless, the relationship between balance and university adaptation was significantly stronger for the students with than without disabilities. For students without disabilities, having a higher perception of their ability to balance multiple roles was associated with a higher reported grade. Moreover, for both students with and without disabilities, being more academically resourceful was associated with higher self-efficacy scores $\left(r_{\text {without }}=.49\right.$, and $\left.r_{\text {with }}=.59\right)$, university adaptation $\left(r_{\text {without }}=\right.$ .41 , and $\left.r_{\text {with }}=.53\right)$, and reported grades $\left(r_{\text {without }}=.38\right.$, and $\left.r_{\text {with }}=.30\right)$, with $p_{s}<.001$.

Moderating role of balance on academic resourcefulness, academic self-efficacy, university adaptation and grades for students with and without disabilities. To assess the moderating role of balancing perceptions on the relationship between academic resourcefulness, academic self-efficacy, university adaptation, grades (dependent variables), and disability grouping (independent variable), separate hierarchical multiple regression analyses were conducted for each of the dependent variables. At step 1 of the regression, centred balanced scores and disability grouping were entered, accounting for $29 \%$ 
of the variance in academic resourcefulness, $13 \%$ of the variance in academic self-efficacy scores, $9 \%$ of the variance in university adaptation, and $6.6 \%$ of the variance in reported grades. For academic self-efficacy, university adaptation, and grades, only the perception of being able to balance multiple roles uniquely contributed to the prediction. For academic resourcefulness, both variables uniquely contributed to the prediction, such that students having higher balance perceptions, $s r^{2}=25.3 \%, p<.001$, and without a disability, $s r^{2}=1.2 \%, p$ $=.004$, were more likely to be more academically resourceful. The cross-product of balance perception and disability grouping was entered at step 2, but failed to significantly add to the prediction of academic resourcefulness, academic self-efficacy, or grades (all $p>.1, R_{\text {change }}^{2}$ $=0 \%$ ), indicating that balance perception did not affect those with and without disabilities differently for these three variables. However, for university adaptation, the cross product of balance perception and disability grouping significantly contributed an additional $1.3 \%$ of the variance to the prediction of university adaptation $(p=.007)$. Based on the regression analysis, Figure 1 illustrates that students perceiving themselves as poorly able to balance multiple roles were less adapted at university, especially if they had a disability. For students who perceived they balanced academic and non-academic activities quite well, adaptation scores were much higher but, interestingly, more so for students with disabilities.

Table 3. Bivariate Relationships between Balance and Academic Self-efficacy, University Adaptation, and Academic Resourcefulness

\begin{tabular}{llllc}
\hline Variable & $\begin{array}{c}\text { Students without } \\
\text { disabilities }\end{array}$ & $\begin{array}{c}\text { Students with } \\
\text { disabilities }\end{array}$ & Z test** & $\begin{array}{c}\text { Significance } \\
P\end{array}$ \\
\hline Self-efficacy & $.34^{*}$ & $.40^{*}$ & -0.76 & .45 \\
Adaptation & $.22^{*}$ & $.45^{*}$ & -2.59 & .01 \\
Resourcefulness & $.52^{*}$ & $.49^{*}$ & 0.47 & .62 \\
Reported grade & $.30^{*}(n=323)$ & $.16^{\text {ns }}(n=141)$ & 1.49 & .14 \\
\hline
\end{tabular}

${ }^{*} p<.001$ for the bivariate correlations

${ }_{*}^{*}$ Fisher's Z test (column 3) was used to determine if correlations between balance and the listed variables were significantly different (column 4) for students with and without disabilities

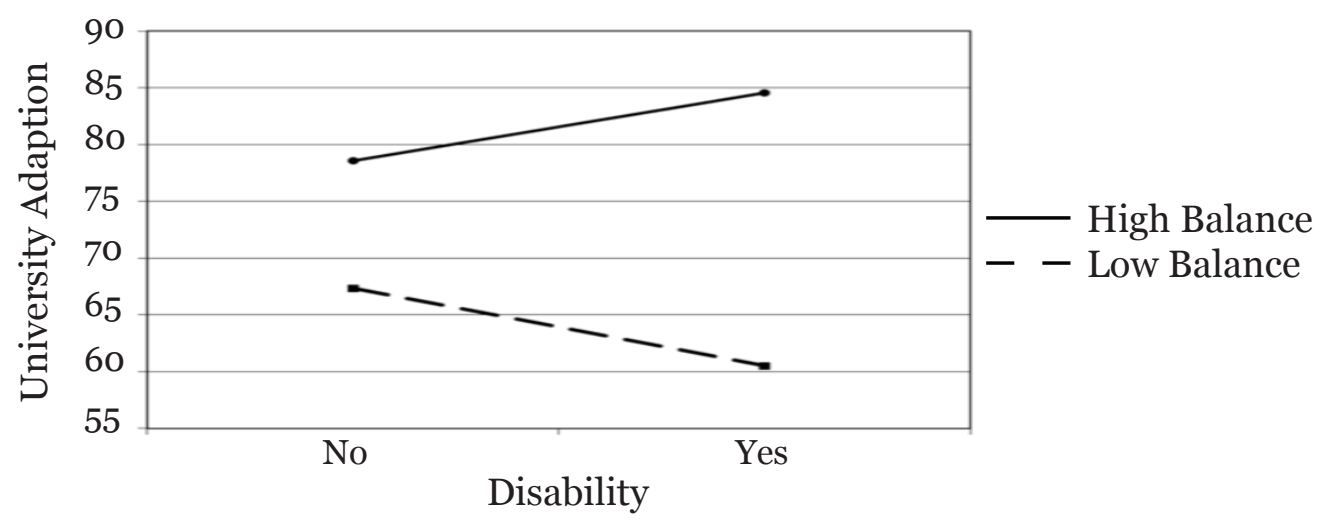

Figure 1. Balance perception as a moderator of the relationship between student grouping and university adaptation. Hierarchical regression was used to determine the equations representing students having a high versus low balance perception. 


\section{Discussion}

Today, Canadian university students are diverse: students often have multiple obligations (e.g., work and family), and more students with disabilities are accessing higher education (McCloy \& DeClou, 2013). Students with disabilities may have additional obligations and stresses at university because they must organize their accommodations for learning. The current study revealed that a similar proportion of students with and without disabilities participated in various non-academic activities, including employment, social activities, and family obligations. Furthermore, perceived ability to balance academic and non-academic activities was associated with higher levels of academic selfefficacy and academic resourcefulness to the same degree for students with and without disabilities. As has been reported in other studies (Kennett 1994, Kennett \& Keefer 2006; Kennett \& Reed 2009), academic resourcefulness was related to greater beliefs in one's academic abilities, better university adaptation, and higher grades for both groups of students. Hence, regardless of grouping, it appears that in order to be confident in the ability to balance multiple roles, that is, being a high achiever and socially adjusted at university, require a student to be resourceful.

Despite the similarities between the groups, this study found that there were some important differences in the university experiences of those with and without disabilities. Students with disabilities had fewer course hours per week, yet they reported studying as much as students without disabilities. Accommodations for learning often require extra hours to re-format assignments, use assistive technologies, and seek help from counsellors and tutors (Eckes \& Ochoa 2005). This additional time needed for learning, unfortunately, may impact the ability of students with disabilities to carry out both academic and non-academic activities. Although a similar proportion of students in our study engaged in non-academic activities, students with disabilities were observed to spend significantly fewer hours participating in them. This was not surprising given that students with disabilities reported being less able to balance their academic and non-academic activities. Being fully integrated into the university is both a social (developing relationships) and academic (meeting learning challenges) endeavour. Our study, however, did not ask students to report on the number of hours they spend in different non-academic activities and knowing this information would assist stakeholders in planning non-academic activities. For instance, if students with disabilities show only fewer hours of social activities, but similar hours of employment and family obligation, then the reasons for this could be better assessed. Regardless, the many academic requirements that students with disabilities must handle (e.g., preparing for their accommodations for learning in addition to studying) may act as a barrier to full participation in non-academic activities. Even though university policies around access to accommodations for learning (e.g., minimal wait times, easy access to assistive technology, and electronic textbooks) could result in improved ability for students with disabilities to balance their multiple roles, these institutions may face systemic barriers (e.g., availability of resources, funding, and published formats available), confining their ability to accommodate these students.

If poorer perception of being able to manage one's multiple roles is directly related to students' university experience of accommodations for learning, there are two aspects of accommodation that might be interfering with balance perception. First, as noted above 
(Eckes \& Ochoa, 2005), accommodations themselves take time scheduling, learning software, waiting for appropriate formats, and dealing with professors' requirements, which can create heightened stress for the student, taking time away from both study time and non-academic activities. Secondly, providing many accommodations, beyond student need, could promote dependency, which conflicts with learning to manage time. For example, giving students considerable extra time for assignments could unintentionally suggest to them that time management is not important. Ohler, Levinson, and Baker (1996) found that students with disabilities receiving many accommodations were less able to develop a career path than those receiving few, if any, accommodations, and Reed et al. (2006) reported that alumni with disabilities said that they were best prepared for success in their careers by understanding their own disability and learning to manage time.

Although the idea that a high number of accommodations could promote dependency is sensitive and speculative, it may be one worth investigating, given some research has supported this (e.g. Ohler et al., 1996). As a first step, regression approaches between balance perception, measures of academic preparation and the number of academic accommodations, where level of functionality is controlled, would determine if there are negative relationships among a greater number of accommodations, less preparedness, and a lower balance perception. Nonetheless, recognizing accommodations are necessary, universities should encourage multiple sources (e.g., student learning services, academic programs, disabilities centres, library) to consider ways to help students learn and practice time management skills, as well as other valuable academic strategies to control stress when faced with academic challenges. While we have argued that the need for accommodation places a burden on students with disabilities, it is also likely that other factors such as lack of accessibility for non-academic activities, disability management, and difficulties in setting up complex accommodations also affect a student's ability to manage time.

One way to promote the ability to balance multiple roles is to include resourcefulness in academic courses that students take. It is acknowledged that skill development comes from many sources (e.g., learning communities and co-curricular professional development), and programs have been developed to teach university students key academic skills, such as how to write critically and use the library, along with methods to manage academic and everyday life stress, with great success. Past research supports the usefulness of these programs for students with and without disabilities. For example, using a pre-test and post-test design in an academic course, Reed et al. (2009) examined the effectiveness of course-based interventions (e.g., teaching resourcefulness skills in an academic course) versus non-course-based interventions (e.g., help sessions at the disabilities centre) for students with learning disabilities. Reed et al. (2009) found that the course-intervention group had greater improvements in resourcefulness, academic self-efficacy, and grades compared to students in other intervention groups. In another study, Reed, Kennett, Lewis, and Lund-Lucas (2011) found that the benefits of interventions brought forward in an academic course for students with and without learning disabilities were the same; significant pre- to post-testing increases in academic resourcefulness and self-efficacy were observed for both groups of students. Extending this finding, the current study outcomes support that interventions incorporating modules on resourcefulness (coping with academic stress) may be particularly beneficial in learning to balance multiple roles. 
The capability to balance these roles is likely affected by students' academic and nonacademic experience, which was not controlled in this study and is a limitation. In this study, for example, the students in the disabilities group tended to be slightly older than the non-disabled students and had been enrolled in university longer. This is not surprising, given that students with disabilities, as shown here, often take fewer courses each term. However, time in university should increase adaptation to university and academic resourcefulness. Regardless, in the current study, the students with disabilities were less often in their first year but were not more adapted to university and were less resourceful than their non-disabled, younger counterparts. In short, this group was not advantaged due to age and time in university. Also important, balance perceptions were associated with both university adaptation and academic resourcefulness, and the advantage of those who perceive they can balance academic and non-academic requirements, regardless of disability status, highlights the need to find ways to help all students establish a sense of balance. Providing programs that teach key academic skills along with methods to manage academic and everyday life stress is one approach.

In the current study, students with disabilities were treated as a single group due to the small sample sizes of specific disability types. It is possible that with larger subsamples of student disability groups some differences would have been revealed, especially given the diversity of experience for students with different disabilities. However, one difficulty in any classification of disabilities is that these categories are generally based on diagnosis, not functionality, and this is a particularly important issue for students with multiple disabilities. Even within single disability types (e.g., visual impairment, learning disability) there are great and unique differences among students in terms of functionality. We did not ask students with disabilities about their level of accommodation, their functional abilities, or the time they spend each week on accommodations. Controlling for disabled students' functionality may explain their lower ability to balance their multiple roles and eliminate some of the differences observed between the with- and without-disability student groups. Thus, the possibility that the level of functionality and accommodation negatively impacts both balance perception and resourcefulness needs to be the focus of future research.

One further limitation of this study is the single institutional nature of this work. It is entirely possible that this single university has policy and student norms that differ from other institutions. While we believe that our outcomes can be generalized to students at other universities, based on studies that show potential sources of student stresses in dealing with accommodations (Eckes and Ochoa, 2005; Vogel et al., 2007), we also acknowledge that the unique nature of single institutions could also affect students' ability to balance and cope with obligations. Moreover, data in this project were collected solely on undergraduate students. How these results could be translated to students in graduate school, professional education programs, or Canadian colleges is not clear. These educational environments are very different from undergraduate environments and, as such, so are student obligations. Although, data from this study may not predict outcomes from these other institutions, studies at these institutions examining students' ability to cope with academic stressors and balance their obligations would be worthwhile.

In summary, this study demonstrated that both students with and without disabilities are advantaged if they perceive that they are able to balance their academic and nonacademic activities. Balance perception was strongly related to academic resourcefulness, suggesting that teaching students these skills would be highly fruitful, especially for those 
having limited resourcefulness skills. More academically resourceful students were also found to be more academically efficacious and adjusted at university, and they reported higher grades. Moreover, if their balance perception was negative, students with disabilities were considerably less adapted to university, in comparison to their non-disabled peers. Creating university policies around easier access to accommodations for learning and the incorporation of resourcefulness and time-management skills into higher education curriculum would benefit all students.

\section{Acknowledgements}

The authors would like to acknowledge Ron Collis for his technical assistance and Vice Provost Academic Christopher Evans at Ryerson University for an internal research grant that financially supported this study.

\section{Disclosure Statement}

The authors have no financial interest or benefits arising from the direct application of this research.

\section{References}

Akgun, S., \& Ciarrochi, J. (2003) Learned resourcefulness moderates the relationship between academic stress and academic performance. Educational Psychology, 23(3), 287-94.

Canadian University Survey Consortium (CUSC) (2011). Canadian University Survey Consortium 2011 undergraduate university survey. Retrieved from http://www.cuscccreu.ca/publications/CUSC_2011_UG_MasterReport.pdf

Collier, P. J., \& Morgan, D. L. (2008), “Is that paper really due today?”: Differences in first-generation and traditional college students' understandings of faculty expectations. Higher Education, 55(4), 425-446. doi: 10.1007/s10734-007-9065-5

Crombag, H. F. M. (1968). Study motivation and study attitude: Membership of various organizations and its effect on study motivation and study attitudes in freshman students. Groningen, Netherlands: Wolters.

Dunes, L., \& Marx. J. (2007). Balancing work and academics in college: Why do students working 10-19 hours per week excel? Journal of College Student Retention, 8(1), 107-120.

Eckes S. E, \& Ochoa, T. A. (2005). Students with disabilities: Transition from high school to higher education. American Secondary Education, 33(3), 6-20.

Galbraith, C. S., \& Merrill G. B. (2015). Academic performance and burnout: An efficient frontier analysis of resource use efficiency among employed university students. Journal of Further and Higher Education, 39(2), 255-277. Retrieved from http://dx.doi. org/10.1080/0309877X.2013.858673

Goff, A. M. (2011). Stressors, academic performance, learned resourcefulness in baccalaureate nursing students. International Journal of Nursing Education Scholarship, $8(1), 1-20$. 
Holmes, V. (2008). Working to live. Why university students balance full-time study and employment.EducationandTraining,5O(4),305-314.doi:10.1108/00400910810880542

Hornsby D. J., \& Osman R, (2014). Massification in higher education: Large classes and student learning. Higher Education, 67(6), 711-9. doi: 10.1007/s10734-014-9733-1

Howell, D. C. 2013. Mediating and moderating variables. In Statistical methods for psychology. (8th ed., pp. 551-556). Belmont, CA: Wadsworth.

Kennett, D. J. (1994). Academic self-management counseling: Preliminary evidence for the importance of learned resourcefulness on program success. Studies in Higher Education 19(3), 295-307.

Kennett, D. J., \& K. Keefer, K. (2006). Impact of learned resourcefulness and theories of intelligence on academic achievement of university students. Educational Psychology, 26(3), 441-457. doi: 10.1080/01443410500342062.

Kennett, D. J., Reed, M. J., \& Stuart, A. (2013). The impact of reasons for attending university on academic resourcefulness and adjustment. Active Learning in Higher Education, 14(2), 123-133. doi: 10.1177/1469787413481130

Kennett, D. J., \& Reed M. J. (2009). Factors influencing academic success and retention following a 1st-year post-secondary success course. Education Research and Evaluation, 15(2), 153-188. doi: 10.1080/13803610902804382

Kennet, D.J.,Young, A.M., \& Cantanzaro, M.(2009).Variables contributing to academic success in an intermediate statistics course: The importance of learned resourcefulness. Educational Psychology, 29(7), 815-830. doi: 10.1080/01443410903305401

King, J. E. (1999). Helping students balance work, borrowing and college. About Campus, 4(4), 17-22.

Marshall, K. (2010). Employment patterns of post-secondary students. Perspectives, September, 5-17, Statistics Canada Catalogue no. 75-001-x.

McCloy, U., \& DeClou, L. (2013). Disability in Ontario: Postsecondary education participation rates, student experience and labour market outcomes. Toronto, ON: Higher Education Quality Council of Ontario. Retrieved from http://heqco.ca/ SiteCollectionDocuments/At\%20Issue\%20-\%20Disability\%20in\%20ON_ENG.pdf

McWhirter, B. T., Burrow-Sanchez, J. J., \& Townsend, K. C. (2008). Measuring learned resourcefulness in college students: Factor structure of the self control schedule (SCS). College Student Journal, 42(4), 1099-1109.

Ohler, D. L., Levinson, E. M., \& Baker, W. F. (1996). Career maturity in college students with learning disabilities. The Career Development Quarterly, 44(3), 278-285.

Ogilvie, K. K., \& Eggleton, A. (2011). Opening the door: Reducing barriers to postsecondary education in Canada. Standing Senate Committee on Social Affairs, Science and Technology. Retrieved from http://www.parl.gc.ca/content/sen/committee/411/ soci/rep/repo6dec11-e.pdf

Ontario Human Rights Commission (2005) The opportunity to succeed: Achieving barrier-free education for students with disabilities. Retrieved from http://www.ohrc. on.ca/en/opportunity-succeed-achieving-barrier-free-education-students-disabilities 
Ontario Human Rights Commission (2008). Policy and guidelines on disability and the duty to accommodate. Retrieved from http://www.ohrc.on.ca/sites/default/files/ policy\%20and\%20guidelines\%20on\%20disability\%20and\%20the\%20duty\%20to\%20 accommodate.pdf

Prudence, C. C., \& Li-Tien, W. (2013). Who benefits from the massification of higher education in Taiwan? Chinese Education Society, 45(5-6), 8-20. doi: 10.2753/CED10611932450501

Reed, M. J. (2016). University massification and teaching non-traditional university students. Invited chapter In J. Arvanitakis \& D. Hornsby D. (Eds.), Universities, the Citizen Scholar, and the Future of Higher Education (pp. 137-154). New York, NY: Palgrave Macmillan.

Reed, M. J., \& Curtis, K. (2012). Experiences of Students with visual impairment in Canadian higher education. Journal of Visual Impairment and Blindness, 106(7), 414425 .

Reed, M. J., Kennett, D. J., Lewis, T., \& Lund-Lucas E. (2011). The relative benefits found for students with and without learning disabilities taking a first year university preparation course. Active Learning in Higher Education, 12(2), 133-142. doi: $10.1177 / 1469787411402483$

Reed, M. J., Kennett, D. J., Lewis, T., Lund-Lucas, E., Stallberg, C., \& Newbold, I. L. (2009). The relative effects of university success courses and individualized interventions for students with learning disabilities. Higher Education Research \& Development, 28(4), 385-399. doi: 10.1080/07294360903067013

Reed, M. J., Lund-Lucas, E. \& Lewis, T. (2006). Student, alumni and parent perspectives on access to post-secondary education and services for students with learning disabilities: Experiences at two Ontario universities. Higher Education Perspectives 2(3), 50-65.

Rosado, D. L., \& David, M. E. (2006). A massive university or a university for the masses? Continuity and change in higher education in Spain and England, Journal of Education Policy, 21(3), 343-365. doi: 10.1080/02680930600600630

Rosenbaum M. (1980). A schedule for assessing self-control behaviours: Preliminary findings. Behavior Therapy, 11, 109-21.

Rossi F (2010). Massification, competition and organizational diversity in higher education: Evidence from Italy. Studies in Higher Education, 33(3), 277-300.

Statistics Canada (2015). Co-occurring disabilities, by type, aged 15 years or older with disabilities, Canada, 2012. Retreived from http://www.statcan.gc.ca/pub/89654-x/2015001/tbl/tblo4-eng.htm

Stebleton, M. J., \& Soria, K. M. (2012). Breaking down barriers. Academic obstacles of first generation students at research universities. The Learning Assistance Review, 17(2), 7-19.

Strapp, C. M., \& Farr, R. J. (2010). To get involved or not: The relation among extracurricular involvement, satisfaction, and academic achievement. Teaching of Psychology, 37(1), 50-54. doi: 10.1080/00986280903425870 
Vogel, G., Fresko, B., \& Wertheim, C. (2007). Peer tutoring for college students with learning disabilities: Perceptions of tutors and tutees. Journal of Learning Disabilities, 4o(6), 485-493.

Van Rhijn, T. M., \& Lero D. (2014). The influence of self-efficacy beliefs for student parents attending university. International Journal of Lifelong Education, 33(4), 541555. http://dx.doi.org/10.1080/02601370.2014.884178

Webber, K. L., Krylow, R. B., \& Q. Zhang, Q. (2013). Does involvement really matter? Indicators of college student success and satisfaction. Journal of College Student Development, 54(6), 591-611. doi: 10.1353/csd.2013.0090

\section{Contact Information}

Maureen J. Reed

Department of Psychology

Ryerson University

mreed@ryerson.ca

Maureen Reed, PhD, is an associate professor in the Department of Psychology at Ryerson University in Toronto. She has expertise in and focuses on research into information processing, and higher education and methods to improve academic success for non-traditional students, including those with and without disabilities.

Deborah J. Kennett is a full professor in the Department of Psychology and director of the Psychology Graduate Program at Trent University, Peterborough, Ontario. Her professional interests focus on coping strategies, school and work transitions, and health promotion, with special emphasis on program development to promote personal achievement and well-being. 